\title{
Article
}

\section{The Honey Bee: An Active Biosampler of Environmental Pollution and a Possible Warning Biomarker for Human Health}

\author{
Marianna Martinello*(D, Chiara Manzinello, Nicoletta Dainese, Ilenia Giuliato, Albino Gallina \\ and Franco Mutinelli iD
}

Citation: Martinello, M.; Manzinello, C.; Dainese, N.; Giuliato, I.; Gallina, A.; Mutinelli, F. The Honey Bee: An Active Biosampler of Environmental Pollution and a Possible Warning Biomarker for Human Health. Appl. Sci. 2021, 11, 6481. https://doi.org/ 10.3390/app11146481

Academic Editor: Simone Morais

Received: 23 June 2021

Accepted: 11 July 2021

Published: 14 July 2021

Publisher's Note: MDPI stays neutral with regard to jurisdictional claims in published maps and institutional affiliations.

Copyright: (c) 2021 by the authors. Licensee MDPI, Basel, Switzerland. This article is an open access article distributed under the terms and conditions of the Creative Commons Attribution (CC BY) license (https:// creativecommons.org/licenses/by/ $4.0 /)$.
Istituto Zooprofilattico Sperimentale delle Venezie, NRL for Honey Bee Health, 35020 Legnaro, PD, Italy; cmanzinello@izsvenezie.it (C.M.); ndainese@izsvenezie.it (N.D.); igiuliato@izsvenezie.it (I.G.); agallina@izsvenezie.it (A.G.); fmutinelli@izsvenezie.it (F.M.)

* Correspondence: mmartinello@izsvenezie.it

\begin{abstract}
Member states of the European Union are required to ensure the initiation of monitoring programs to verify honey bee exposure to pesticides, where and as appropriate. Based on 620 samples of dead honey bees-42 of pollen, 183 of honey and 32 of vegetables-we highlighted the presence, as analyzed by liquid and gas chromatography coupled with tandem mass spectrometric detection, of many active substances, mainly tau-fluvalinate, piperonyl butoxide, chlorpyrifos and chlorpyrifosmethyl, permethrin and imidacloprid. Among the active substances found in analyzed matrices linked to honey bee killing incidents, 38 belong to hazard classes I and II, as methiocarb, methomyl, chlorpyrifos, cypermethrin and permethrin, thus representing a potential risk for human health. We have shown that, at different times between 2015 and 2020, during implementation of the Italian national guidelines for managing reports of bee colony mortality or depopulation associated with pesticide use, pesticide pollution events occurred that could raise concern for human health. Competent authorities could, as part of a One Health approach, exploit the information provided by existing reporting programs on honey bees and their products, in view of the close correlation to human health, animal health and ecosystem health.
\end{abstract}

Keywords: biomonitoring; environment; health; honey bee; humans; pesticides; plant protection products (PPP); pollutants; sentinels

\section{Introduction}

Globalization has allowed agricultural production to grow much faster than in the past. Despite the benefits-above all, economic - derived from intensive farming, many studies have demonstrated the harmful effects caused to the health of people directly and indirectly exposed to the pesticides used to protect crops [1-5]. Pesticides are used to control various pests and disease carriers in order to keep crops healthy. Before an active substance can be used in a plant protection product (PPP), it must be approved through a rigorous evaluation process, including risk assessments for human health and the environment. The use of pesticides is governed in the European Union by Regulation (EC) No. 1107/2009 of the European Parliament and of the Council concerning the placing of plant protection products on the market, repealing Council Directives 79/117/EEC and 91/414/EEC [6]. This regulation has since been further amended. Regulation (EC) No. 396/2005 provides indications on the maximum residue levels of pesticides in or on food and feed of plant and animal origin [7]. Human exposure to these contaminants can be acute or chronic, depending on the type of contact occurring for professional, dietary or environmental reasons. Pathologies related to pesticide exposure can take various forms, as tumors and neurodegenerative, respiratory, reproductive, developmental, and metabolic diseases $[1,2,8]$.

A biomonitoring program could be a useful approach to assess the uptake and potential health risks caused by direct and indirect exposure to these environmental contaminants. 
Biomonitoring is the use of living organisms to collect information about the surrounding environment. Honey bees (Apis mellifera) are highly sensitive to most chemicals and are a well-known indicator of environmental pollution [9-13]. Honey bees commonly feed within $1.5 \mathrm{~km}$ and, exceptionally, up to 10-12 km of their hive, depending on their need for food and its availability [14]. Limiting factors are the need for optimal weather conditions for foraging (20-25 ${ }^{\circ} \mathrm{C}$ and dry weather) [10]. Furthermore, below 7-10 ${ }^{\circ} \mathrm{C}$, honey bees show the tendency to remain in the hive, and above $38^{\circ} \mathrm{C}$, their activity decreases due to heat [10]. During flights and foraging activity, their hair-covered body causes electrical charge accumulation on its surface due to friction with the air, favoring the attraction of airborne substances, including pollen and pollutants $[15,16]$. During foraging flights, honey bees collect pollen, nectar, plant resins, honeydew and water, which are taken into the hive and stored, being at the same time also valid "samplers" of organic and inorganic chemicals in the environment, which they bring back to the colony $[17,18]$. Finally, they are easy insects to breed, having modest dietary needs and being almost ubiquitous [19]. Hence, honey bees (and their products) are reliable ecological detectors, and many studies have shown their feasibility as bioindicators of environmental pollution by pesticides [18-20], heavy metals [21-24], radionuclides [25,26], polycyclic aromatic hydrocarbons [17,27], and other pollutants, such as brominated flame retardants [28], vehicle-derived ultrafine particulate [29], and microplastics [30].

Honey bees can be considered a living monitoring system of various aspects of the ecosystem since their health is influenced by multiple environmental factors, both natural and mediated by human activity [31], such as climate trends, quick reduction in the areas where plants used by bees as a source of nectar or pollen are grown, bee diseases and infestation with Varroa destructor, in particular, phytosanitary treatments, and beekeeping practices [32]. In recent decades, a decline in honey bee colonies has been reported by beekeepers from around the world [20,33]. In Italy, since 2003, significant honey bee mortality has been recorded in springtime, mainly related to the side effects of maize seed dressed with neonicotinoid insecticides [34]. Due to the significant increase in these events in 2008, a nationwide surveillance network, named ApeNet (2009-2010), was implemented to monitor the health status of beehives and determine the consistency and possible causes of mortality. From about 100 apiaries distributed throughout most of Italy, they increased to 300 with approximately 3000 beehives in 2011 in the framework of the BeeNet project (2011-2014). The Italian Ministry of Agriculture, Food and Forestry Policies [35] funded both initiatives. In this context, a Bee Emergency Service Team (BEST) was established, managing beekeepers' reports, contributing to the assessment of events' severity, organizing and participating in field interventions, and coordinating the technicians recruited for their deployment, in agreement with and in support of the competent authorities [36]. During these monitoring studies, 126 honey bee samples related to honey bee-killing incidents, confirmed by BEST, were analyzed. Approximately 50\% were positive for at least one active substance, the most frequently detected being imidacloprid, chlorpyrifos, thiachloprid, chlothianidin and thiametoxam. The number of detected pesticides was positively related to the size of the agricultural area surrounding the apiaries [37].

Commission Directive 2010/21/EU requires that member states ensure that monitoring programs are carried out where and as appropriate to verify the real exposure of honey bees to pesticides in areas used by bees for foraging [38]. Furthermore, since beekeepers still frequently report bee deaths at certain times of the year, and considering the strong public attention to this problem, various Italian regions deemed it appropriate to adopt a more systematic approach to the management of bee mortality where pesticide poisoning is suspected. Accordingly, the General Directorate of Animal Health and Veterinary Medicines of the Italian Ministry of Health issued the "Linee guida per la gestione delle segnalazioni di moria o spopolamento degli alveari connesse all'utilizzo di agrofarmaci" (Guidelines for the management of reports of death or depopulation of bee colonies related to the use of plant protection products) [39]. They provide operational indications for the management of death and depopulation events of the hives in order to make the intervention activity 
more homogeneous both for the procedures adopted in the field and in the laboratory. The aim of the guidelines is to collect information on the causes of death and depopulation of hives with particular regard to the use of PPPs [39]. In addition, the implementation of a biomonitoring program on the environmental exposure of honey bees to pesticides could have an interesting return for human epidemiological studies. Considering the well-known risks related to direct and indirect human exposure to pesticides [1-5], verification of their presence in honey bees and their products could serve as an early warning system for public health interventions.

Our study reports on the presence of pesticide residues in dead honey bees and associated matrices received at our laboratory from 2015 to 2020, following implementation of the above guidelines. Besides providing relevant, possibly obvious, considerations about honey bee health, our findings are presented within the framework of the valuable role that honey bees could play in a nationwide monitoring system, with implications for public health.

\section{Materials and Methods}

\subsection{Sample Collection and Location}

Following a beekeeper's notification of a honey bee death incident, official, speciallytrained veterinarians from the Local Health Authority, in the presence of the beekeeper, sampled and shipped the dead honey bee samples and related matrices to our laboratory (the matrices were not always sampled and sent, due to an unresolved conflict of competence between the Veterinary and Food Hygiene and Nutrition Services). The official veterinarians worked in accordance with the aforementioned guidelines in order to harmonize the procedure used by the different apiaries and beekeepers. Samples consisted of 250-1000 dead honey bees collected in properly sealed and identified containers. Optionally, samples of pollen, honeycomb and vegetable (such as leaves, flowers, corn seedlings, and maize, depending on the plants present near the hives affected by honey bee killing incidents) matrices were also collected. All samples were stored at $-20^{\circ} \mathrm{C}$ until delivery to the territorially competent veterinary institute (IZS), and then until toxicological analysis. The samples considered in this paper were delivered to our laboratory between 2015 and 2020. Figure 1 shows the cumulative location of all matrix sampling points and mortality events in Italy during 2015 to 2020 . The presence on the territory of reference institutions, and the sensitivity of veterinary services and of beekeepers strongly affected the response to honey bee mortality events in terms of samples collected and sent to the laboratory as depicted in the map. In total, 620 samples of dead honey bees, 42 of pollen, 145 of honeycomb, 46 of honey (collected from the nest), 32 of vegetable, and 3 of other materials (liquid dripping from the bottom board, suspected material collected on propolis, and hive debris) were collected in the framework of bee killing episodes and sent to the veterinary institutes as specified above.

\subsection{Chemicals}

Methanol, acetonitrile, heptane (suitable for HPLC gradient grade), formic acid, ammonium formate (reagent grade), acetic acid (glacial ReagentPlus ${ }^{\circledR}, \geq 99 \%$ ), Supel ${ }^{\mathrm{TM}} \mathrm{QuE}$ Citrate Extraction Tubes, and Supel ${ }^{\mathrm{TM}} \mathrm{QuE}$ PSA/C18 (EN) Cleanup Tubes, used to extract and purify samples, were purchased from Sigma-Aldrich. High purity water was prepared using a Milli-Q water purification system (Millipore, Burlington, MA, USA). Analyticalgrade (98-99.9\% purity) standards of pesticides were supplied by Sigma-Aldrich and are listed in the Supplemental Data, Table S1. Single standard solutions were prepared in methanol at a concentration of $1000 \mathrm{mg} / \mathrm{L}$. The working standard solutions were prepared by mixing the appropriate amounts of single standard solutions and diluting with methanol to a final concentration of 10 and $1 \mathrm{mg} / \mathrm{L}$. All solutions were stored in the dark in $10 \mathrm{~mL}$ amber bottles at $-20^{\circ} \mathrm{C}$. 


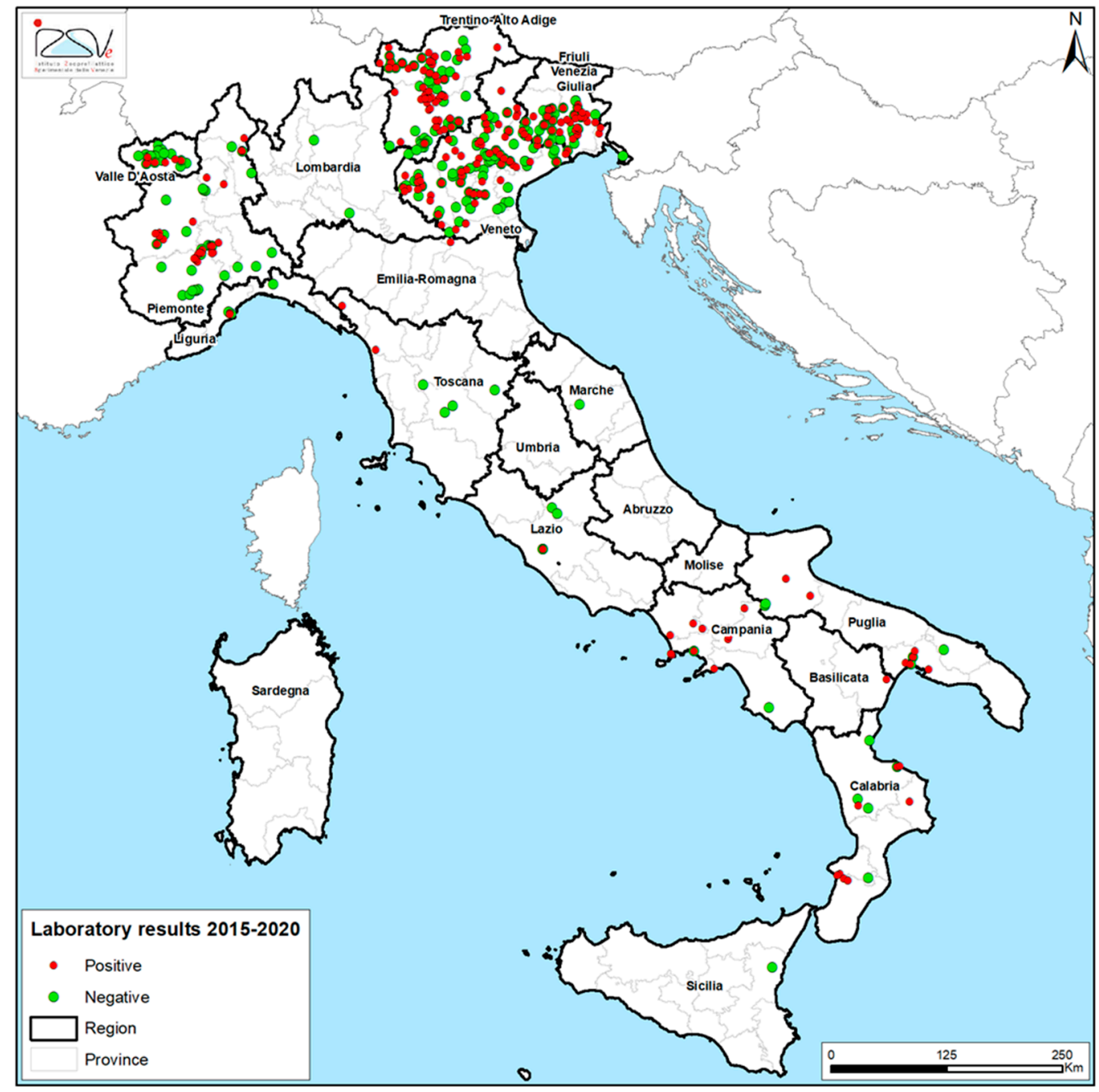

Figure 1. Cumulative location of the sampling points in Italy for all matrices related to reported mortality events from 2015 to 2020.

\subsection{Sample Extraction}

The samples were prepared as described in Martinello et al. 2019 [16]. The samples were pulverized with a crushing mill (A11 basic IKA-Werke GmbH \& Co. KG, Staufen, Germany), cooled with liquid nitrogen and then processed in duplicate for subsequent analysis, using both liquid chromatography (LC) and gas chromatography (GC) techniques. The samples were weighted ( $2 \mathrm{~g}$ for honey bees and beeswax and $1 \mathrm{~g}$ for pollen and vegetables) into a centrifuge tube, and the surrogate standard clothianidin-D3 (50 $\mu \mathrm{g} / \mathrm{kg}$ ) was added and allowed to stand for $10 \mathrm{~min}$. Then, $10 \mathrm{~mL}$ of water was added and vortexed for $5 \mathrm{~min}$. Acetonitrile with $0.1 \%$ acetic acid $(10 \mathrm{~mL})$ was added, vortexed for $20 \mathrm{~min}$ and cooled at $-20^{\circ} \mathrm{C}$. QuEChERS salts EN method (sodium citrate $1 \mathrm{~g}$, sodium hydrogen citrate sesquihydrate $0.5 \mathrm{~g}$, magnesium sulphate $4 \mathrm{~g}$ and sodium chloride $1 \mathrm{~g}$ ) were added and vigorously shaken for $1 \mathrm{~min}$. The mixture was centrifuged, and $7 \mathrm{~mL}$ of supernatant was transferred to a tube with dispersive SPE Fatty Samples EN salts (magnesium sulphate $900 \mathrm{mg}$, PSA $150 \mathrm{mg}$, and C18 $150 \mathrm{mg}$ ), vortexed for $1 \mathrm{~min}$ and centrifuged; $4 \mathrm{~mL}$ of the supernatant was evaporated to dryness under vacuum at $45^{\circ} \mathrm{C}$. The residue was dissolved in $0.5 \mathrm{~mL}$ of reconstitution solution $(5 \mathrm{mM}$ ammonium formiate in water with $0.1 \%$ formic acid and $5 \mathrm{mM}$ ammonium formiate in methanol with $0.1 \%$ formic acid, 1:1 $v / v$ and the internal standard imidacloprid-D4, $50 \mu \mathrm{g} / \mathrm{kg})$ and PTFE filtered $(0.45 \mu \mathrm{m}$ pore size $)$ for analysis by UPLC-MS/MS (Ultra Pressure LC coupled with tandem mass spectrometry). The samples analyzed using GC-MS/MS were reconstituted with $0.5 \mathrm{~mL}$ of heptane and 
PTFE filtered. Both instruments were programmed in MRM (Multiple Reaction Monitor) mode with two selected transitions per molecule.

\subsection{LC-MS/MS Analysis}

The analysis was performed on a Shimadzu LCMS-8040 and, from 2017 onwards, on a Shimadzu LCMS-8045, both with a tandem quadrupole analyzer in MRM spectrum mode, using an electron spray ionization source in both positive and negative ionization mode. The chromatography was performed on a Raptor (Restek Corporation, Bellefonte, PA, USA) biphenyl column $(10 \mathrm{~cm} \times 2.1 \mathrm{~mm}, 2.7 \mu \mathrm{m}$-particles $)$, thermostated at $35^{\circ} \mathrm{C}$. Mobile phase (A) was performed with $5 \mathrm{mM}$ ammonium formiate in water with $0.1 \%$ formic acid and (B) with $5 \mathrm{mM}$ ammonium formiate in methanol with $0.1 \%$ formic acid. The chromatographic eluting conditions were optimized as follows: from $3 \%$ to $10 \% \mathrm{~B}$ (0-1 $\mathrm{min}$ ), from $10 \%$ to $55 \%$ B (1-3 min), from $55 \%$ to $100 \%$ B (3-10.5 min), 100\% B maintained for $2.5 \mathrm{~min}$, from $100 \%$ to $3 \% \mathrm{~B}$ in $0.01 \mathrm{~min}$, followed by re-equilibration to $3 \% \mathrm{~B}$ for 3 minutes. The flow rate was $0.4 \mathrm{~mL} / \mathrm{min}$ and the injection volume was $2 \mu \mathrm{L}$. Quantitative and qualitative analyses were performed with LabSolution Insight software based on the two most intensive fragment ion transitions. A matrix-matched calibration was used for quantification.

\subsection{GC-MS/MS Analysis}

The analysis was performed on a Shimadzu GCMS-TQ8040 equipped with Phenomenex ZB-Semivolatiles columns ( $30 \mathrm{~m}, 0.25 \mathrm{~mm}$ ID, $0.25 \mu \mathrm{m})$ and a tandem mass spectrometry detector. The sample volume of $1 \mu \mathrm{L}$ was injected in splitless mode at an injector temperature of $270{ }^{\circ} \mathrm{C}$. The GC temperature was programmed as follows: $60^{\circ} \mathrm{C}$ (2 min) increased by $70{ }^{\circ} \mathrm{C} / \mathrm{min}$ to $200^{\circ} \mathrm{C}$ and increased by $6{ }^{\circ} \mathrm{C} / \mathrm{min}$ to $300^{\circ} \mathrm{C}(2 \mathrm{~min})$, for a total analysis run time of $23 \mathrm{~min}$. The ion source and interface temperature were held at $230^{\circ} \mathrm{C}$ and $280^{\circ} \mathrm{C}$, respectively. Quantitative and qualitative analyses were performed with LabSolution Insight software based on the two most intensive fragment ion transitions. A matrix-matched calibration was used for quantification.

\subsection{Data Interpretation}

The concentrations of active substances found in honey bees are conventionally expressed as ng/bee, but we decided to tabulate the detected concentrations in $\mathrm{mg} / \mathrm{kg}$ since our work focused on the potential danger posed by the detected active substances to humans rather than to pollinating insects. The oral LD50 value is a statistical estimate of the number of $\mathrm{mg}$ of active substance per $\mathrm{kg}$ of body weight needed to kill-if ingested- $50 \%$ of a large population of experimental animals [38]. Our work used the LD50 in rat (mammal) values, as it gives a clear, immediate indication of the dangerousness of the substances detected in the different matrices during the reported honey bee mortality incidents. The classification of pesticides by hazard is based primarily on acute oral, dermal and inhalation toxicity to the rat since these determinations are standard procedures in toxicology [40]. When different oral, dermal or inhalation LD50 values are reported in the literature, the lowest is reported and used as the reference value, unless there are clear indications that a higher value is more reliable. The classification criteria based on mammalian toxicity are guide points intended to estimate the potential danger of the isolated substances to humans. In Tables 1 and 2, LD50 values preceded by " $c$ " refer to values in a wider-than-normal range, adopted for classification purposes, as provided in the 2019 edition of the "WHO Recommended Classification of Pesticides by Hazard and Guidelines to Classification" [40]. This document was approved by the 28th World Health Assembly in 1975 and has since become widely accepted. Individual active substances are classified in a series of tables, in different classes according to the oral or dermal toxicity of the active substance: class Ia, extremely hazardous; class Ib, highly hazardous; class II, moderately hazardous; class III, slightly hazardous; and class $\mathrm{U}$, unlikely to present acute hazard. The acute toxicity hazard categories adopted by WHO are aligned with the Globally Harmonized System of classification and labeling of chemicals (GHS). 
Table 1. Summary of honey bee samples collected from bee-killing incidents analyzed between 2015 and 2020.

\begin{tabular}{|c|c|c|c|c|c|c|c|}
\hline Year & Samples & $\begin{array}{l}\text { Positive } \\
\text { (\%) }\end{array}$ & $\begin{array}{l}\text { No. ASs } \\
\text { Identified }\end{array}$ & $\begin{array}{l}\text { Most Frequent ASs } \\
\text { (Prevalence \%) }\end{array}$ & $\begin{array}{l}\text { Range } \\
\text { (mg/kg) }\end{array}$ & $\begin{array}{l}\text { Oral LD } \\
(\mathrm{mg} / \mathrm{kg})^{\circ}\end{array}$ & $\begin{array}{c}\text { Most } \\
\text { Concentrated AS } \\
(\mathrm{mg} / \mathrm{kg})\end{array}$ \\
\hline \multirow[t]{4}{*}{2015} & \multirow[t]{4}{*}{68} & \multirow[t]{4}{*}{41} & \multirow[t]{4}{*}{20} & Fluvalinate (50) & $0.01-0.615$ & $>3000$ & \multirow[t]{4}{*}{ Permethrin 207.500} \\
\hline & & & & Piperonyl butoxide (25) & $0.016-5.020$ & $>7500$ & \\
\hline & & & & Cypermethrin (14) & $0.130-76.02$ & c250 & \\
\hline & & & & Chlorpyrifos (14) & $0.011-5.612$ & 135 & \\
\hline \multirow[t]{5}{*}{2016} & \multirow[t]{5}{*}{112} & \multirow[t]{5}{*}{42} & \multirow[t]{5}{*}{22} & Chlorpyrifos (26) & $0.021-16.888$ & 135 & \multirow[t]{5}{*}{ Permethrin 1346.65} \\
\hline & & & & Permethrin (26) & $\begin{array}{c}0.032- \\
1346.650\end{array}$ & c220 & \\
\hline & & & & Tetramethrin (26) & $\begin{array}{c}0.010- \\
710.960\end{array}$ & $>5000$ & \\
\hline & & & & Piperonyl butoxide (23) & $\begin{array}{c}0.567- \\
668.270\end{array}$ & $>7500$ & \\
\hline & & & & Fluvalinate (21) & $0.040-0.950$ & $>3000$ & \\
\hline \multirow[t]{3}{*}{2017} & \multirow[t]{3}{*}{95} & \multirow[t]{3}{*}{50} & \multirow[t]{3}{*}{22} & Fluvalinate (42) & $0.010-10.180$ & $>3000$ & \multirow[t]{3}{*}{ Permethrin 30.03} \\
\hline & & & & Chlorpyrifos (27) & $0.010-0.370$ & 135 & \\
\hline & & & & Methomyl (17) & $0.010-7.650$ & 17 & \\
\hline \multirow[t]{4}{*}{2018} & \multirow[t]{4}{*}{85} & \multirow[t]{4}{*}{74} & \multirow[t]{4}{*}{36} & Fluvalinate (35) & $0.031-0.141$ & $>3000$ & \multirow{4}{*}{$\begin{array}{l}\text { Dimethoate } 16.474 \\
\quad\left(\mathrm{LD}_{50}=\mathrm{c} 150\right)\end{array}$} \\
\hline & & & & Imidacloprid (14) & $0.014-0.562$ & 450 & \\
\hline & & & & Etofenprox (13) & $0.013-0.035$ & $>10,000$ & \\
\hline & & & & Methiocarb (13) & $0.010-0.465$ & 20 & \\
\hline \multirow[t]{3}{*}{2019} & \multirow[t]{3}{*}{147} & \multirow[t]{3}{*}{43} & \multirow[t]{3}{*}{34} & Fluvalinate (46) & $0.011-5.148$ & $>3000$ & \multirow{3}{*}{$\begin{array}{c}\text { Tetramethrin } \\
15.043\end{array}$} \\
\hline & & & & Imidacloprid (14) & $0.012-40.260$ & 450 & \\
\hline & & & & $\begin{array}{l}\text { Chlorpyrifos-methyl } \\
\text { (13) }\end{array}$ & $0.022-1.078$ & $>3000$ & \\
\hline \multirow[t]{5}{*}{2020} & \multirow[t]{5}{*}{113} & \multirow[t]{5}{*}{44} & \multirow[t]{5}{*}{35} & Fluvalinate (32) & $0.010-0.399$ & $>3000$ & \multirow[t]{5}{*}{ Permethrin 80.68} \\
\hline & & & & Etofenprox (22) & $0.013-0.045$ & $>10,000$ & \\
\hline & & & & $\begin{array}{c}\text { Chlorpyrifos-methyl } \\
\text { (18) }\end{array}$ & $0.023-0.490$ & $>3000$ & \\
\hline & & & & Permethrin (12) & $0.020-80.680$ & c220 & \\
\hline & & & & Piperonyl butoxide (12) & $0.010-39.980$ & $>7500$ & \\
\hline
\end{tabular}

AS $=$ active substances; ${ }^{\circ}$ tested in rat.

Table 2. Summary of other matrices collected from bee-killing incidents analyzed between 2015 and 2020.

\begin{tabular}{|c|c|c|c|c|c|c|c|c|}
\hline Year & $\begin{array}{l}\text { No. of } \\
\text { Samples }\end{array}$ & Matrix & $\begin{array}{l}\text { Positive } \\
\qquad(\%)\end{array}$ & $\begin{array}{l}\text { No. ASs } \\
\text { Identified }\end{array}$ & $\begin{array}{l}\text { Most Frequent ASs } \\
\text { (Prevalence \%) }\end{array}$ & $\begin{array}{l}\text { Range } \\
\text { (mg/kg) }\end{array}$ & $\begin{array}{l}\text { Oral LD }{ }_{50} \\
(\mathrm{mg} / \mathrm{kg})^{\circ}\end{array}$ & $\begin{array}{c}\text { Most Concentrated } \\
\text { AS } \\
(\mathrm{mg} / \mathrm{kg})\end{array}$ \\
\hline \multirow[t]{5}{*}{2015} & 18 & & 67 & 12 & tau-fluvalinate (83) & $0.038-2.29$ & $>3000$ & tau-fluvalinate 2.29 \\
\hline & & & & & tetraconazole (25) & $0.010-0.015$ & 1031 & \\
\hline & 15 & comb & 67 & 10 & tau-fluvalinate (100) & $0.038-2.29$ & $>3000$ & \\
\hline & 1 & honey & 100 & 2 & - & & & \\
\hline & 2 & vegetable & 50 & 3 & - & & & \\
\hline \multirow[t]{6}{*}{2016} & 39 & & 56 & 15 & tau-fluvalinate (46) & $0.10-0.96$ & $>3000$ & $\begin{array}{l}\text { propamocarb } 3.58 \\
\left(\mathrm{LD}_{50}=8600\right)\end{array}$ \\
\hline & & & & & $\begin{array}{c}\text { metalaxyl/permethrin } \\
\text { (14) }\end{array}$ & $\begin{array}{c}0.015- \\
0.19 / 0.010-2.06\end{array}$ & $670 / c 220$ & \\
\hline & 28 & comb & 54 & 7 & tau-fluvalinate (67) & $0.10-0.96$ & $>3000$ & \\
\hline & 3 & pollen & 67 & 1 & metalaxyl (100) & $0.015-0.016$ & 670 & \\
\hline & 3 & honey & 0 & 0 & - & & & \\
\hline & 5 & vegetable & 60 & 6 & - & & & \\
\hline
\end{tabular}


Table 2. Cont.

\begin{tabular}{|c|c|c|c|c|c|c|c|c|}
\hline Year & $\begin{array}{l}\text { No. of } \\
\text { Samples }\end{array}$ & Matrix & $\begin{array}{l}\text { Positive } \\
\text { (\%) }\end{array}$ & $\begin{array}{l}\text { No. ASs } \\
\text { Identified }\end{array}$ & $\begin{array}{l}\text { Most Frequent ASs } \\
\text { (Prevalence \%) }\end{array}$ & $\begin{array}{l}\text { Range } \\
(\mathrm{mg} / \mathrm{kg})\end{array}$ & $\begin{array}{l}\text { Oral LD } \\
(\mathrm{mg} / \mathrm{kg})^{\circ}\end{array}$ & $\begin{array}{c}\text { Most Concentrated } \\
\text { AS } \\
(\mathbf{m g} / \mathbf{k g})\end{array}$ \\
\hline \multirow[t]{4}{*}{2017} & 23 & & 57 & 10 & $\begin{array}{l}\text { tau-fluvalinate (31) } \\
\text { chlorpyrifos (23) }\end{array}$ & $\begin{array}{l}0.010-4.59 \\
0.011-0.10\end{array}$ & $\begin{array}{l}>3000 \\
135\end{array}$ & tau-fluvalinate 4.59 \\
\hline & 11 & comb & 91 & 9 & tau-fluvalinate (60) & $0.17-4.59$ & $>3000$ & \\
\hline & 7 & pollen & 43 & 3 & tau-fluvalinate (67) & $0.010-0.032$ & $>3000$ & \\
\hline & 5 & honey & 0 & 0 & - & & & \\
\hline \multirow[t]{6}{*}{2018} & 36 & & 83 & 26 & $\begin{array}{c}\text { tau- } \\
\text { fluvalinate/methiocarb } \\
(50)\end{array}$ & $\begin{array}{c}0.031- \\
1.91 / 0.010-70.65\end{array}$ & $>3000 / 20$ & $\begin{array}{l}\text { folpet } 511.10 \\
\left(\mathrm{LD}_{50}>10,000\right)\end{array}$ \\
\hline & & & & & coumaphos $(27)$ & $0.011-0.72$ & 7.1 & \\
\hline & 11 & comb & 91 & 10 & tau-fluvalinate $(100)$ & $0.031-1.91$ & $>3000$ & \\
\hline & 10 & pollen & 90 & 14 & tau-fluvalinate $(67)$ & $0.034-0.68$ & $>3000$ & \\
\hline & 7 & honey & 71 & 1 & methiocarb (100) & $0.011-0.68$ & 20 & \\
\hline & 8 & vegetable & 75 & 12 & deltamethrin (67) & $0.046-0.12$ & c135 & \\
\hline \multirow[t]{6}{*}{2019} & 73 & & 56 & 27 & tau-fluvalinate (58) & $0.017-95.90$ & $>3000$ & tau-fluvalinate 95.90 \\
\hline & & & & & pyrimethanil (20) & $0.021-0.77$ & 4150 & \\
\hline & 32 & comb & 78 & 16 & tau-fluvalinate (68) & $0.017-0.40$ & $>3000$ & \\
\hline & 14 & pollen & 78 & 11 & $\begin{array}{l}\text { tau- } \\
\text { fluvalinate/pyrimethanil } \\
\text { (27) }\end{array}$ & $\begin{array}{c}34.20- \\
95.90 / 0.021-0.77\end{array}$ & $>3000 / 4150$ & \\
\hline & 25 & honey & 12 & 2 & tau-fluvalinate (67) & $0.029-0.048$ & $>3000$ & \\
\hline & 2 & vegetable & 100 & 6 & - & & & \\
\hline \multirow[t]{7}{*}{2020} & 79 & & 60 & 37 & tau-fluvalinate (69) & $0.013-3.93$ & $>3000$ & $\begin{array}{c}\text { cypermethrin } 569.91 \\
\left(L D_{50}=c 250\right)\end{array}$ \\
\hline & & & & & coumaphos (31) & $0.013-0.65$ & 7.1 & \\
\hline & 48 & comb & 71 & 24 & tau-fluvalinate (82) & $0.013-3.93$ & $>3000$ & \\
\hline & 8 & pollen & 25 & 6 & - & & & \\
\hline & 5 & honey & 0 & 0 & - & & & \\
\hline & 15 & vegetable & 60 & 17 & - & & & \\
\hline & 3 & other* & 67 & 5 & - & & & \\
\hline
\end{tabular}

AS $=$ active substance; ${ }^{\circ}$ tested in rat; ${ }^{*}$ see description in the text.

\section{Results}

Tables 1 and 2 summarize the main results of the reporting and analytical activities carried out from 2015 to 2020, following the introduction of the Ministerial Guidelines of 31 July 2014 for the management of honey bee-killing incidents relating to honey bees and other matrices, respectively.

As shown in Table 1, the pyrethroid tau-fluvalinate is certainly the most commonly found substance, followed by chlorpyrifos (referred to as chlorpyrifos-ethyl), chlorpyrifosmethyl (both organophosphates), and piperonyl butoxide (a synergist component of pesticide formulations). The active substances were detected in a wide range of concentrations. Observing the results in Table 1, we see that a potentially dangerous concentration, not only for honey bees, was detected for one active substance only, namely, permethrin, a pyrethroid found in a sample of dead bees in 2016 at a concentration of $1346.65 \mathrm{mg} / \mathrm{kg}$, i.e., about six times its oral LD50 value (c220 mg/kg). In 2020 a significant concentration, albeit lower than the LD50 value, was again detected, as were residues of methomyl (a carbamate) in 2017 (7.65 mg/kg) and cypermethrin (a pyrethroid) in 2015 (76.02 mg/kg).

Table 2 reports the results of the other matrices linked to honey bee-killing incidents received at our laboratory. Other matrices were usually honeycombs, pollen, honey, vegetable materials (leaves, flowers, corn seedlings, maize), and other samples, including liquid dripping from the bottom board, suspected material collected on propolis, and hive debris. Again, tau-fluvalinate was the most frequently detected active substance, followed by coumaphos (an organophosphate). In general, the detected concentrations were much lower than the LD50 values, with the exception, in 2018, of a vegetable matrix sample (leaves) found to be positive for methiocarb (a carbamate) at a concentration of $70.65 \mathrm{mg} / \mathrm{kg}$ (oral LD50 $20 \mathrm{mg} / \mathrm{kg}$ ) and, in 2020, of a sample of a suspect material deposited on propolis inside the beehive, testing positive for cypermethrin at a concentration of $569.91 \mathrm{mg} / \mathrm{kg}$, 
i.e., more than twice its oral LD50 value (c250 mg/kg). Furthermore, honeycombs were not considered as indicators of contamination at the time point of the reported bee killing episodes since they remain within the beehive longer than other matrices and beeswax can accumulate residues of different pesticides of both beekeeping and agricultural origin.

\section{Discussion}

Honey bees can be contaminated with toxic substances in many different ways, both during foraging flights and within the hive [41-43]. They can come into contact directly or indirectly with crop spraying treatments or dust dispersed during coated seed sowing [44,45], and can ingest contaminated guttation droplets [46], irrigation water [47], nectar and pollen [48,49]. A further potential route of exposure to active substances for bees is inside the hive, through beekeeper treatments against Varroa mites [50] and contact with residue-contaminated comb wax [51,52]. The miticides tau-fluvalinate and coumaphos, a pyrethroid and an organophosphate, respectively, which were frequently detected in the analyzed matrices, are active substances of veterinary medicines currently authorized for use in beekeeping in the EU [50]. However, coumaphos has not been available for this purpose in Italy since 2008. Tau-fluvalinate belongs to class III and coumaphos to class Ib, but their detected concentrations were relatively low.

Many active substances not directly related to in-hive treatments were also found. Chlorpyrifos (class II) and chlorpyrifos-methyl (class III) (both organophosphates) are among the most commonly used insecticides in Europe for controlling insect pests on a range of crops, such as cereals (including barley and wheat), fruit (such as apples, pears, grapes and strawberries), and vegetables (including carrots and cabbages) [53]. These crops are all widely grown across Italy, which could explain why they were frequently identified in the samples of dead bees received at our laboratory. The European Commission requested a statement from the European Food Safety Authority (EFSA) on the available outcomes of the human health risk assessment on chlorpyrifos and chlorpyrifosmethyl [54,55]. EFSA identified concerns about possible genotoxic and neurological effects during development, supported by epidemiologic data indicating the effects in children. As to whether the recorded toxicological effects met the criteria for classification as toxic to reproduction, it was not possible to establish the safe exposure level or toxicological reference values for the two substances. The European Commission, thus, adopted Regulations (EU) 2020/17 and 2020/18 concerning the non-renewal of approval of the active substances chlorpyrifos-methyl and chlorpyrifos [56,57].

Piperonyl butoxide is a synergist used in a wide variety of insecticides to enhance active substance performance and is included in over 2500 pesticides used in agricultural, commercial, and household products [58]. It is a synergist in pyrethrin, pyrethroid, rotenone, and carbamate pesticide formulations [59] without intrinsic insecticidal activity, and is used, in particular, for the post-harvest treatment of cereals. It is not considered a pesticide active substance in the EU [60], being defined as "not yet assessed at EU level" in the EU Pesticide database [61]. In the WHO Recommended Classification of Pesticides by Hazard, it belongs to the category of active substances unlikely to present acute hazard in normal use [40].

Permethrin (class II) is a pyrethroid insecticide, which is moderately toxic to humans as an irritant and can be toxic to the central nervous system [53]. It is not authorized for use in PPP in the EU, where its use in agricultural was banned in 2003 under Directive 91/414/EEC (subsequently repealed by Regulation (EC) No. 1107/2009) based on assessment of the environmental fate and ecotoxicology of the substance in aquatic ecosystems. It is instead approved as a biocide [62], specifically under Commission Implementing Regulation (EU) No. 1090/2014, which approved permethrin as an existing active substance for use in biocidal products for product types 8 and 18 [63]. Furthermore, permethrin is approved for the topical treatment of lice infestation and scabies in humans [64]. Nonetheless, besides being among the active substances most frequently found in dead bees and other matrices, permethrin was also present in very high concentrations in dead bees in 
both 2016 and 2020, at levels up to six times greater than its LD50. Its detection and the concentrations revealed by laboratory investigations suggest that it might have been used to intentionally kill honey bee colonies.

The carbamate insecticide methomyl, another active substance no longer approved for use in the EU, was found in dead honey bees in 2017 at a concentration equivalent to about half its LD50. Given its danger to human health, this is undoubtedly a significant finding. It is a carbamate insecticide classified as highly hazardous to humans (class Ib), highly toxic to mammals, and a cholinesterase inhibitor, exhibiting moderate to high toxicity to most fauna and flora [53].

Cypermethrin (class II) is a pyrethroid insecticide approved for use in the EU. It is highly toxic to most aquatic species and honey bees; although it is an irritant, no serious human health issues have been identified. Significant concentrations of the compound (about one third of its LD50) were found in dead bees in 2015. Particularly high concentrations (more than twice its LD50) were detected in a sample suspected of bee poisoning in 2020.

Another of the most frequently identified active substances in both honey bees and other matrices is the carbamate, methiocarb. It meets the criteria for class Ib (highly hazardous active substances in pesticides), being highly toxic to mammals, a cholinesterase inhibitor, and a neurotoxin. It is also highly toxic to most fauna and flora, including honey bees [53]. Accordingly, methiocarb is no longer approved for use in the EU. Unsurprisingly, it has quite a low LD50 value $(20 \mathrm{mg} / \mathrm{kg})$. In 2018, a highly significant presence was detected in different samples of honey bees and other matrices, all originating from the same geographical area, particularly in a vegetable matrix sample containing a concentration equivalent to almost four times the LD50. Notably, this sample contained seven other active substances, indicating an excessive use of pesticides, probably constituting a serious hazard not only for the health of honey bees, but also for humans.

Another aspect to consider is that $55 \%$ of the total positive samples contained more than one active substance. This suggests that, despite the relatively low concentration of individual active substances, synergistic effects caused by the presence of different active substances in the area cannot be ruled out. In addition to environmental bioindicators, honey bees could also play a very important role as sentinels for human health risk. The human body acts as a final accumulator of chemical pollutants, which can lead to health problems [65]. The population can be simultaneously or sequentially exposed to several active substances, due to the presence of residues in food, in the environment and in professional settings, which can take different routes (oral, dermal, and inhalation). These combined exposures can pose a risk to human health. Chronic cumulative effects on human health depend on the combination of time-averaged exposures to pesticides that share a common toxicological mechanism of action, while acute cumulative effects are essentially driven by the likelihood of simultaneous exposure to different groups of pesticides over a period of time of a few hours to a few days [66]. The U.S. Environmental Protection Agency (EPA) used this approach with the concept of a "risk cup" to determine the acceptable amount of risk associated with the use of a specific class of pesticides. The calculated risk for a compound is determined and "placed" into the risk cup. Each accepted registration of a compound with a similar mechanism of action is then added to the cup. Once the cup is full, no new registrations are allowed $[67,68]$. The limitation of this approach is that it fails to address chemical synergism and the effects of mixtures of pesticides from multiple classes [68]. The classes of AIs most frequently encountered in our study are pyrethroids (such as tau-fluvalinate, permethrin, etofenprox, cypermethrin), carbamates (such as methomyl and methiocarb) of which piperonyl butoxide-one of the most frequently found active substances-is a synergist, and the class of organophosphates (such as coumaphos, chlorpyrifos and chlorpyrifos-methyl). They belong to cholinesterase-inhibiting insecticides (organophosphates and $\mathrm{N}$-methylcarbamates) and pyrethroid insecticides that are overrepresented in the synergistic mixtures identified so far [69]. However, true synergistic interactions between chemicals are rare and often occur at high concentrations [70]. Addressing the cumulative rather than synergistic effect 
of co-occurring chemicals, using standard models, such as concentration addition, appears, therefore, to be the most important step in the risk assessment of chemical cocktails [70]. The evaluation and prediction of biological responses elicited by interaction of pesticides with each other (pesticide mixtures) requires an integrated, systematic toxicological approach and is a challenge to human and environmental risk assessment as demonstrated by the plethora of publications on the subject $[59,66,69-73]$. The identification of core features of pesticide mixtures at the molecular level, such as gene expression profiles, could be helpful to assess or predict the occurrence of interactive effects giving rise to unpredicted responses [69].

We also report that 38 of the 71 active substances identified during implementation of the Italian guidelines belonged to hazard classes I and II for active substances in pesticides, thus categorizing them as extremely $(n=2)$, highly $(n=8)$ and moderately dangerous $(\mathrm{n}=28)$. Their simultaneous presence, in most cases, with other active substances confirms that honey bees could be very valuable sentinels of environmental health and consequently, of possible hazards to human health.

In addition, all officially reported bee-killing incidents can be easily georeferenced with maps, showing their distribution across a given territory. As shown in Figure 1, most bee-killing incidents reported to the competent authorities occurred in northern Italy, with a lower number of reported cases scattered across central and southern Italy. The agricultural areas in the north were widely represented by non-irrigated arable land, fruit trees (predominantly apple orchards), berry plantations, olive groves, and vineyards; and by non-irrigated arable land, fruit trees (citrus), olive groves, and vineyards in the central and southern regions [74]). Mapping indirect honey-bee monitoring activities is a helpful means to more precisely locate affected areas and trends in events, permitting the implementation of further public health investigations to trace, back to their origin, identified pesticides or other dangerous substances, including unauthorized ones-such as permethrin, methiocarb, and methomyl-with the legal implications that this entails. To alleviate the negative effects of pesticide use, more measures need to be adopted to improve pesticide application and the related regulations. Effective monitoring and management of pesticides could not only reduce their use, but also protect the ecosystem and public health [75]. The One Health concept is based on the close interconnection between human, animal and environmental health, and emphasizes how human health depends on a healthy, functioning ecosystem [76]. Consequently, further biomonitoring actions should be deployed by competent authorities following a One Health approach, leveraging information provided by honey bees and their products. Honey bees and honey bee products can act as a natural, passive, inexpensive monitoring system capable of revealing potentially alarming or dangerous situations for human well-being and public health.

\section{Conclusions}

The present work highlights the presence of hazardous pesticide residues in honey bees and other related samples belonging to toxicity classes Ia, Ib and II, alone or in combination, including unauthorized ones. We have summarized the results obtained through implementation, by the competent local health authorities, of Italian national guidelines for managing reports of bee colony death or depopulation related to the use of PPP. Although specifically addressed to the reporting of honey bee-killing incidents, we have shown that the various pesticide pollution events that have occurred could potentially represent a risk also for human health, particularly when methiocarb, methomyl, chlorpyrifos, cypermethrin and permethrin were detected. The cumulative effect of co-occurring chemicals, using standard models, such as concentration addition, seems to be the most important approach in the risk assessment of chemical cocktails. Furthermore, the evaluation and prediction of biological responses elicited by the interaction of pesticides with each other (pesticide mixtures) implies an integrated, systematic toxicological approach, and is a challenge to human and environmental risk assessment. Honey bees are closely linked to human well-being through the pollination of wild and agricultural plants and the production 
of honey and other bee products and should be considered in a One Health approach. Eventually, they can also provide valuable information about the ecosystem since their health is determined by many factors related to the environment and to humans.

Supplementary Materials: The following are available online at https: / www.mdpi.com/article/10.3 390/app11146481/s1, Table S1: List of the active substances studied (limit of quantification = $10 \mu \mathrm{g} / \mathrm{kg}$ ).

Author Contributions: Conceptualization, M.M. and F.M.; methodology, M.M. and A.G.; investigation, M.M., C.M., N.D., I.G.; writing-original draft preparation, M.M.; writing—review and editing, M.M. and F.M. All authors have read and agreed to the published version of the manuscript.

Funding: This research received no external funding.

Institutional Review Board Statement: Not applicable.

Informed Consent Statement: Not applicable.

Data Availability Statement: Data available on request due to privacy restrictions.

Acknowledgments: Joanne M. Fleming edited the English text.

Conflicts of Interest: The authors declare no conflict of interest.

\section{References}

1. El-Nahhal, Y. Pesticide residues in honey and their potential reproductive toxicity. Sci. Total Environ. 2020, 741, 139953. [CrossRef]

2. Mostafalou, S.; Abdollahi, M. Pesticides: An update of human exposure and toxicity. Arch. Toxicol. 2017, 91, 549-599. [CrossRef]

3. Rani, L.; Thapa, K.; Kanojia, N.; Sharma, N.; Singh, S.; Singh Grewal, A.; Lal Srivastav, A.; Kaushal, J. An extensive review on the consequences of chemical pesticides on human health and environment. J. Clean. Prod. 2021, 283, 124657. [CrossRef]

4. Sabarwala, A.; Kumara, K.; Singha, R.P. Hazardous effects of chemical pesticides on human health-Cancer and other associated disorders. Environ. Toxicol. Pharmacol. 2018, 63, 103-114. [CrossRef]

5. Yuan, X.; Pan, Z.; Jin, C.; Ni, Y.; Fu, Z.; Jin, Y. Gut microbiota: An underestimated and unintended recipient for pesticide-induced toxicity. Chemosphere 2019, 227, 425-434. [CrossRef]

6. Regulation (EC) No 1107/2009 of the European Parliament and of the Council of 21 October 2009 Concerning the Placing of Plant Protection Products on the Market and Repealing Council Directives 79/117/EEC and 91/414/EEC. OJ L 309, 24 November 2009; pp. 1-50. Available online: https:/ / eur-lex.europa.eu/legal-content/EN/TXT/?uri=celex\%3A32009R1107 (accessed on 9 July 2021).

7. Regulation (EC) No 396/2005 of the European Parliament and of the Council of 23 February 2005 on Maximum Residue Levels of Pesticides in or on Food and Feed of Plant and Animal Origin and Amending Council Directive 91/414/EEC. OJ L 70, 16 March 2005; pp. 1-16. Available online: https:/ / eur-lex.europa.eu/legal-content/EN/ALL/?uri=celex\%3A32005R0396 (accessed on 9 July 2021).

8. Ramírez-Santana, M.; Zúñiga-Venegas, L.; Corral, S.; Roeleveld, N.; Groenewoud, H.; van der Velden, K.; Scheepers, P.T.J.; Pancetti, F. Association between cholinesterase's inhibition and cognitive impairment: A basis for prevention policies of environmental pollution by organophosphate and carbamate pesticides in Chile. Environ. Res. 2020, 186, 109539. [CrossRef] [PubMed]

9. Celli, G.; Maccagnani, B. Honey bees as bioindicators of environmental pollution. Bull. Insectol. 2003, 56, 137-139.

10. Bargańska, Z.; Ślebioda, M.; Namieśnik, J. Honey bees and their products: Bioindicators of environmental contamination. Crit. Rev. Environ. Sci. Technol. 2016, 46, 235-248. [CrossRef]

11. Porrini, C.; Sabatini, A.G.; Girotti, S.; Ghini, S.; Medrzycki, P.; Grillenzoni, F.; Bortolotti, L.; Gattavecchia, E.; Celli, G. Honey bees and bee products as monitors of the environmental contamination. Apiacta 2003, 38, 63-70.

12. Lim, S.; Yunusbaev, U.B.; Ilyasov, R.A.; Lee, H.S.; Kwon, H.W. Abdominal contact of fluvalinate induces olfactory deficit in Apis mellifera. Pest. Biochem. Physiol. 2020, 164, 221-227. [CrossRef]

13. Ilyasov, R.; Lim, S.; Lee, M.L.; Kwon, H.W.; Nikolenko, A. Effect of miticides amitraz and fluvalinate on reproduction and productivity of honey bee Apis mellifera. Uludag Bee J. 2021, 21, 21-30.

14. Pham-Delègue, M.H. Les Abeilles; La Martinière Editions Paris: Paris, France, 1998; p. 47.

15. Bonmatin, J.M.; Giorio, C.; Girolami, V.; Goulson, D.; Kreutzweiser, D.P.; Krupke, C.; Liess, M.; Long, E.; Marzaro, M.; Mitchell, E.A.; et al. Environmental fate and exposure; neonicotinoids and fipronil. Environ. Sci. Pollut. Res. 2015, 22, 35-67. [CrossRef] [PubMed]

16. Vaknin, Y.; Gan-Mor, S.; Bechar, A.; Ronen, B.; Eisikowitch, D. The role of electrostatic forces in pollination. Plant Syst. Evol. 2000, 222, 133-142. [CrossRef]

17. Lambert, O.; Piroux, M.; Puyo, S.; Thorin, C.; Larhantec, M.; Delbac, F.H.; Pouliquen, H. Bees, honey and pollen as sentinels for lead environmental contamination. Environ. Pollut. 2012, 170, 33-43. [CrossRef] [PubMed] 
18. Martinello, M.; Manzinello, C.; Borin, A.; Avram, L.E.; Dainese, N.; Giuliato, I.; Gallina, A.; Mutinelli, F. A Survey from 2015 to 2019 to investigate the occurrence of pesticide residues in dead honeybees and other matrices related to honeybee mortality incidents in Italy. Diversity 2020, 12, 15. [CrossRef]

19. Girotti, S.; Ghini, S.; Maiolini, E.; Bolelli, L.; Ferri, E.N. Trace analysis of pollutants by use of honeybees, immunoassays, and chemiluminescence detection. Anal. Bioanal. Chem. 2013, 405, 555-571. [CrossRef]

20. Porrini, C.; Mutinelli, F.; Bortolotti, L.; Granato, A.; Laurenson, L.; Roberts, K.; Gallina, A.; Silvester, N.; Medrzycki, P.; Renzi, T.; et al. The Status of Honey Bee Health in Italy: Results from the Nationwide Bee Monitoring Network. PLoS ONE 2016, 11, e0155411. [CrossRef]

21. Perugini, M.; Manera, M.; Grotta, L.; Abete, M.C.; Tarasco, R.; Amorena, M. Heavy metal (Hg, Cr, Cd, and Pb) contamination in urban areas and wildlife reserves: Honeybees as bioindicators. Biol. Trace Elem. Res. 2011, 140, 170-176. [CrossRef]

22. Ruschioni, S.; Riolo, P.; Minuz, R.L.; Stefano, M.; Cannella, M.; Porrini, C.; Isidoro, N. Biomonitoring with honeybees of heavy metals and pesticides in nature reserves of the Marche region (Italy). Biol. Trace Elem. Res. 2013, 154, 226-233. [CrossRef]

23. Zarić, N.M.; Deljanin, I.; Ilijević, K.; Stanisavljević, L.; Ristić, M.; Gržetić, I. Honeybees as sentinels of lead pollution: Spatiotemporal variations and source appointment using stable isotopes and Kohonen self-organizing maps. Sci. Total Environ. 2018, 642, 56-62. [CrossRef]

24. Bellucci, V.; Lucci, S.; Bianco, P.; Ubaldi, A.; Felicioli, A.; Porrini, C.; Mutinelli, F.; Battisti, S.; Spallucci, V.; Cersini, A.; et al. Monitoring honey bee health in five natural protected areas in Italy. Vet. Ital. 2019, 55, 15-25. [PubMed]

25. Horn, U.; Helbig, M.; Molzahan, D.; Hentshel, E.J. The transfer of Ra-226 to honey and the possible use of the honey bee as a bioindicator in the uranium mining area of the Wismut region (Germany). Apidologie 1996, 27, 211-217. [CrossRef]

26. Wieczorek, J.; Kaczor, M.; Romańczyk, G.; Grońska, M.; Boryło, A. Radioactivity of honey in central and southern Poland. J. Environ. Radioact. 2020, 222, 106376. [CrossRef] [PubMed]

27. Amorena, M.; Visciano, P.; Giacomelli, A.; Marinelli, E.; Sabatini, A.G.; Medrzycki, P.; Oddo, L.P.; De Pace, F.M.; Belligoli, P.; Di Serafino, G.; et al. Monitoring of levels of polycyclic aromatic hydrocarbons in bees caught from beekeeping: Remark 1. Vet. Res. Commun. 2009, 1, 165-167. [CrossRef]

28. Mohr, S.; García-Bermejo, A.; Herrero, L.; Gómara, B.; Costabeber, I.H.; González, M.J. Levels of brominated flame retardants (BFRs) in honey samples from different geographic regions. Sci. Total Environ. 2014, 472, 741-745. [CrossRef]

29. Papa, G.; Capitani, G.; Capri, E.; Pellecchia, M.; Negri, I. Vehicle-derived ultrafine particulate contaminating bees and bee products. Sci. Total Environ. 2021, 750, 141700. [CrossRef]

30. Edo, C.; Fernández-Alba, A.R.; Vejsnæs, F.; van der Steen, J.J.M.; Fernández-Piñas, F.; Rosal, R. Honeybees as active samplers for microplastics. Sci. Total Environ. 2021, 767, 144481. [CrossRef]

31. EFSA (European Food Safety Authority). Scientific Committee. Scientific Opinion on a systems-based approach to the environmental risk assessment of multiple stressors in honey bees. EFSA J. 2021, 19, 6607.

32. Jacques, A.; Laurent, M.; EPILOBEE Consortium; Ribière-Chabert, M.; Saussac, M.; Bougeard, S.; Budge, G.E.; Hendrikx, P.; Chauzat, M.P. A pan-European epidemiological study reveals honey bee colony survival depends on beekeeper education and disease control. PLoS ONE 2017, 12, e0172591. [CrossRef]

33. Goulson, D.; Nicholls, E.; Botías, C.; Rotheray, E.L. Bee declines driven by combined stress from parasites, pesticides, and lack of flowers. Science 2015, 347, 1255957. [CrossRef]

34. Greatti, M.; Barbattini, R.; Stravisi, A.; Sabatini, G.; Rossi, S. Presence of the a.i. imidacloprid on vegetation near corn fields sown with Gaucho ${ }^{\circledR}$ dressed seeds. Bull. Insectol. 2006, 59, 99-103.

35. Rete Rurale. Available online: https:/ / www.reterurale.it/flex/cm/pages/ServeBLOB.php/L/IT/IDPagina/1369 (accessed on 3 January 2020).

36. Porrini, C.; Sgolastra, F.; Renzi, T. Bee Emergency Service Team (BEST): Bee losses and mortality reports in Italy (2012-2014). Bull. Insectol. 2014, 67, 294.

37. Mutinelli, F.; Sgolastra, F.; Porrini, C.; Medrzycki, P.; Bortolotti, L.; Granato, A.; Gallina, A.; Lodesani, M. The status of honey bee health in Italy: Results from the nationwide monitoring network. In Proceedings of the XI European Congress of Entomology, Naples, Italy, 2-6 July 2018; p. 318.

38. Commission Directive 2010/21/EU of 12 March 2010 Amending Annex I to Council Directive 91/414/EEC as Regards the Specific Provisions Relating to Clothianidin, Thiamethoxam, Fipronil and Imidacloprid. OJEU L 65, 13 March 2010; pp. 27-30. Available online: https:/ / eur-lex.europa.eu/eli/dir/2010/21/oj (accessed on 22 June 2021).

39. Linee Guida Per la Gestione delle Segnalazioni di Moria o Spopolamento degli Alveari Connesse All'utilizzo di Fitofarmaci [Guideline for the Management of Reporting of Mortality or Dwindling of Beehives Linked to the Use of Pesticides] 001616831/07/2014-DGSAF-COD_UO-P. Italian Ministry of Health. 2014. Available online: http:/ /www.izsvenezie.it/linee-guidaper-la-gestione-delle-segnalazioni-di-moria-o-spopolamento-degli-alveari-connesse-allutilizzo-di-fitofarmaci (accessed on 29 November 2020).

40. World Health Organization. WHO Recommended Classification of Pesticides by Hazard and Guidelines to Classification, 2019 ed.; World Health Organization: Geneva, Switzerland, 2020; p. 100.

41. Bogdanov, S. Contaminants of bee products. Apidologie 2006, 37, 1-18. [CrossRef]

42. Johnson, R.M.; Dahlgren, L.; Siegfried, B.D.; Ellis, M.D. Acaricide, fungicide and drug interactions in honey bees (Apis mellifera). PLoS ONE 2013, 8, e54092. [CrossRef] 
43. Mullin, C.A.; Frazier, M.; Frazier, J.L.; Ashcraft, S.; Simonds, R.; vanEngelsdorp, D.; Pettis, J.S. High levels of miticides and agrochemicals in north American apiaries: Implications for honey bee health. PLoS ONE 2010, 5, e9754. [CrossRef]

44. Effects of Coated Maize Seed on Honey Bees. Report Based on Results Obtained from the First Year of Activity of the ApeNet Project. Available online: http:/ / www.reterurale.it/apenet (accessed on 15 January 2021).

45. Sgolastra, F.; Renzi, T.; Draghetti, S.; Medrzycki, P.; Lodesani, M.; Maini, S.; Porrini, C. Effects of neonicotinoid dust from maize seed-dressing on honey bees. Bull. Insectol. 2012, 65, 273-280.

46. Girolami, V.; Mazzon, L.; Squartini, A.; Mori, N.; Marzaro, M.; Di Bernardo, A.; Greatti, M.; Giorio, C.; Tapparo, A. Translocation of neonicotinoid insecticides from coated seeds to seedling guttation drops: A novel way of intoxication for bees. J. Econ. Entomol. 2009, 102, 1808-1815. [CrossRef]

47. Porrini, C. Studi sul ruolo degli agrofarmaci nella sindrome della scomparsa delle api in Italia, nell'ambito del progetto Apenet. APOidea 2010, 2, 20-25.

48. Dively, G.P.; Kamel, A. Insecticide residues in pollen and nectar of a cucurbit crop and their potential exposure to pollinators. J. Agric. Food Chem. 2012, 60, 4449-4456. [CrossRef]

49. Stoner, K.A.; Eitzer, B.D. Movement of soil-applied imidacloprid and thiamethoxam into nectar and pollen of squash (Cucurbita реро). PLoS ONE 2012, 7, e39114. [CrossRef]

50. Mutinelli, F. Veterinary medicinal products to control Varroa destructor in honey bee colonies (Apis mellifera) and related EU legislation-An update. J. Apic. Res. 2016, 55, 78-88. [CrossRef]

51. Wu, J.Y.; Anelli, C.M.; Sheppard, W.S. Sub-lethal effects of pesticide residues in brood comb on worker honey bee (Apis mellifera) development and longevity. PLOS ONE 2011, 6, e14720. [CrossRef]

52. Zhu, W.; Schmehl, D.R.; Mullin, C.A.; Frazier, J.L. Four common pesticides, their mixtures and a formulation solvent in the hive environment have high oral toxicity to honey bee larvae. PLOS ONE 2014, 9, e77547. [CrossRef] [PubMed]

53. PPDB: Pesticide Properties Database. Available online: http://sitem.herts.ac.uk/aeru/ppdb/en/index.htm (accessed on 13 January 2021).

54. EFSA (European Food Safety Authority). Statement on the available outcomes of the human health assessment in the context of the pesticides peer review of the active substance chlorpyrifos. EFSA J. 2019, 17, 5809.

55. EFSA (European Food Safety Authority). Statement on the available outcomes of the human health assessment in the context of the pesticides peer review of the active substance chlorpyrifos-methyl. EFSA J. 2019, 17, 5810.

56. Commission Implementing Regulation (EU) 2020/17 of 10 January 2020 Concerning the Non-Renewal of the Approval of the Active Substance Chlorpyrifos-methyl, in Accordance with Regulation (EC) No 1107/2009 of the European Parliament and of the Council Concerning the Placing of Plant Protection Products on the Market, and Amending the Annex to Commission Implementing Regulation (EU) No 540/2011. OJEU L 7, 13 January 2020; pp. 11-13. Available online: https:/ / eur-lex.europa.eu/ eli/reg_impl/2020/17/oj (accessed on 22 June 2021).

57. Commission Implementing Regulation (EU) 2020/18 of 10 January 2020 Concerning the Non-Renewal of the Approval of the Active Substance Chlorpyrifos, in Accordance with Regulation (EC) No 1107/2009 of the European Parliament and of the Council Concerning the Placing of Plant Protection Products on the Market, and Amending the Annex to Commission Implementing Regulation (EU) No 540/2011. OJEU L 7, 13 January 2020; pp. 14-16. Available online: https:/ / eur-lex.europa.eu/eli/reg_impl/ 2020/18/oj (accessed on 22 June 2021).

58. Rivera-González, K.S.; Beames, T.G.; Lipinski, R.J. Examining the developmental toxicity of piperonyl butoxide as a Sonic hedgehog pathway inhibitor. Chemosphere 2021, 264, 128414. [CrossRef] [PubMed]

59. Pohanish, R. Sittig's Handbook of Pesticides and Agricultural Chemicals, 2nd ed.; William Andrew Publishing: Oxford, UK, 2015; pp. 629-724.

60. Nougadère, A.; Sirot, V.; Cravedi, J.P.; Vasseur, P.; Feidt, C.; Fussell, R.J.; Hu, R.; Leblanc, J.C.; Jean, J.; Rivière, G.; et al. Dietary exposure to pesticide residues and associated health risks in infants and young children-Results of the French infant total diet study. Environ. Int. 2020, 137, 105529. [CrossRef] [PubMed]

61. EU Pesticide Database. Available online: https://ec.europa.eu/food/plant/pesticides/eu-pesticides-db_en (accessed on 15 January 2021).

62. Regulation (EU) No 528/2012 of the European Parliament and of the Council of 22 May 2012 Concerning the Making Available on the Market and Use of Biocidal Products. OJ L 167, 27 June 2012; pp. 1-123. Available online: https:/ / eur-lex.europa.eu/legalcontent/EN/TXT/?uri=CELEX\%3A32012R0528 (accessed on 22 June 2021).

63. Commission Implementing Regulation (EU) No 1090/2014 of 16 October 2014 Approving Permethrin as an Existing Active Substance for Use in Biocidal Products for Product-Types 8 and 18. OJ L 299, 17 October 2014; pp. 10-14. Available online: https:/ / eur-lex.europa.eu/legal-content/EN/TXT/PDF/?uri=CELEX:32014R1090\&from=EN (accessed on 22 June 2021).

64. Centers for Disease Control and Prevention. Available online: https://www.cdc.gov / parasites/ (accessed on 29 January 2021).

65. Graillot, V.; Takakura, N.; Hegarat, L.L.; Fessard, V.; Audebert, M.; Cravedi, J.P. Genotoxicity of pesticide mixtures present in the diet of the French population. Environ. Mol. Mutagen. 2012, 53, 173-184. [CrossRef] [PubMed]

66. Hernández, A.F.; Tsatsakis, A.M.; Alegakis, A. Chapter 13: The problem of risk assessment of pesticide mixtures. In The Problem of Risk Assessment of Pesticide Mixtures Exposure and Risk Assessment of Pesticide Use in Agriculture. Approaches, Tools and Advances, 1st ed.; Colosio, C., Tsatsakis, A., Mandic-Rajcevic, S., Alegakis, A., Eds.; Academic Press: Cambridge, MA, USA, 2020; pp. 329-345.

67. Fenske, R. Organophosphates and the Risk Cup. Agrichem. Environ. News 1999, 163, 6-8. 
68. Lydy, M.; Belden, J.; Wheelock, C.; Hammock, B.; Denton, D. Challenges in regulating pesticide mixtures. Ecol. Soc. $2004,9,1$. [CrossRef]

69. Hernández, A.F.; Gil, F.; Lacasaña, M. Toxicological interactions of pesticide mixtures: An update. Arch. Toxicol. 2017, 91, 3211-3223. [CrossRef] [PubMed]

70. Cedergreen, N. Quantifying synergy: A systematic review of mixture toxicity studies within environmental toxicology. PLoS ONE 2014, 9, e96580. [CrossRef] [PubMed]

71. Bopp, S.K.; Kienzler, A.; Richarz, A.N.; van der Linden, S.C.; Paini, A.; Parissis, N.; Worth, A.P. Regulatory assessment and risk management of chemical mixtures: Challenges and ways forward. Crit. Rev. Toxicol. 2019, 49, 174-189. [CrossRef] [PubMed]

72. Crivellente, F.; Hart, A.; Hernández-Jerez, A.F.; Hougaard Bennekou, S.; Pedersen, R.; Terron, A.; Wolterink, G.; Mohimont, L. Establishment of cumulative assessment groups of pesticides for their effects on the nervous system. EFSA J. 2019, 17, e05800.

73. Craig, P.S.; Dujardin, B.; Hart, A.; Hernández-Jerez, A.F.; Hougaard Bennekou, S.; Kneuer, C.; Ossendorp, B.; Pedersen, R.; Wolterink, G.; Mohimont, L. Cumulative dietary risk characterisation of pesticides that have acute effects on the nervous system. EFSA J. 2020, 18, e06087.

74. Copernicus Land Monitoring Service. Available online: https://land.copernicus.eu/pan-european/corine-land-cover/clc2018 (accessed on 26 January 2021).

75. Liu, Y.; Liu, F.; Pan, X.; Li, J. Protecting the environment and public health from pesticides. Environ. Sci. Technol. 2012, 46, 5658-5659. [CrossRef]

76. Destoumieux-Garzón, D.; Mavingui, P.; Boetsch, G.; Boissier, J.; Darriet, F.; Duboz, P.; Fritsch, C.; Giraudoux, P.; le Roux, F.; Morand, S.; et al. The one health concept: 10 years old and a long road ahead. Front. Vet. Sci. 2018, 5, 14. [CrossRef] 